\title{
A saúde bucal no povo indígena Wajãpi do estado do Amapá
}

\section{The oral health among the Wajãpi indigenous people of Amapá state, Brazil.}

\section{La salud oral en el pueblo indígena Wajãpi del estado de Amapá, Brasil.}

Tiago Araújo Coelho de Souza ${ }^{1}$

Efigênia Ferreira e Ferreira ${ }^{2}$

\section{RESUMO}

Este artigo tem como objetivo descrever alguns aspectos das representações sócioculturais da população indígena Wajãpi/AP, identificar os hábitos $\mathrm{e}$ as transformações nos padrões alimentares deste povo e fazer um paralelo deste contexto com o perfil epidemiológico em saúde bucal. O estudo foi desenvolvido através de uma pesquisa quali-quantitativa, onde através dos registros discursivos, observacionais e epidemiológicos buscou-se conhecer a concepção e a condição de saúde bucal entre os Wajãpi/AP. Os resultados demonstraram que a intensificação do processo de contato com a sociedade nacional introduziu a prática do assalariamento, proporcionou mudanças de hábitos e influenciou o aumento do consumo de alimentos industrializados. A polarização dos componentes que constituem o

1. Doutor em Saúde Pública; Departamento de Odontologia, Faculdade de Ciências da Saúde, Universidade de Brasília.

2. Doutora em Ciência Animal - Epidemiologia. Professora Associada da Faculdade de Odontologia. Universidade Federal de Minas Gerais. índice CPO-D e a condição dentária encontrada evidenciam diferenças no acesso ao tratamento em saúde bucal segundo a localização geográfica das aldeias.

Palavras-chave: odontologia; saúde bucal; povo indígena Wajãpi.

\section{ABSTRACT}

The article aims to present some aspects of the social and cultural representations of the Wajapi indigenous people (Amapá State, Brazil), to identify habits and changes in their alimentary patterns as well as to do a parallel of this context with their epidemiological oral health profile. The study was developed as a quali-quantitative research where interviews, observations and an oral health survey were used to know the conceptions and conditions about the Wajapi's oral health. The results showed that the intensification of the contact with the Brazilian national society introduced the wage payment practice, provided habits modifications and influenced the consumption of industrialized food and alimentary diet changes as well. The polarization of the DMFT components showed differences regarding the 
access to oral health treatment according to the geographical location of the villages.

Key words: dentistry; oral health; Wajãpi indigenous people, Brazil.

\section{RESUMEN}

Este artículo tiene por objetivo describir algunos aspectos de las representaciones socioculturales de la población indígena Wajãpi del Estado de Amapá, Brasil, identificar los hábitos y las transformaciones en los patrones de alimentación de este pueblo y hacer un paralelo de este contexto con el perfil epidemiológico en slud oral. El estudio fue desarrollado por medio de una investigación cuali-cuantitativa, en donde mediante registros discursivos, observacionales y epidemiológicos, se objetivó conocer la concepción y la condición de salud oral entre los indígenas Wajãpi del Estado de Amapá, Brasil. Los resultados demostraron que la intensificación del proceso de contacto con la sociedad nacional introdujo la práctica de la remuneración asalariada, proporcionó cambios de hábitos e tuvo influencia en el aumento del consumo de alimentos industrializados. La polarización de los componentes que constituyen el índice CPO-D y la condición dental encontrada, dejan evidente las diferencias en el acceso al tratamiento en salud oral, según la localización geográfica de las aldeas.

Palabras-clave: odontología; salud oral; indígenas Wajãpi, Brasil.

\section{CONSIDERAÇÕES INICIAIS}

Ao se tentar compreender as concepções e práticas de saúde existentes em grupos sociais específicos percebe-se que os valores culturais determinam a explicação do processo saúde-doença. Nas comunidades indígenas, a contextualização cultural ainda tem sido pouco utilizada pelos programas de saúde como ferramenta consubstancial de auxílio ao modo de pensar e de fazer a atenção em terra indígena.

A população indígena, no Brasil é estimada em aproximadamente 800.000 pessoas, pertencentes a 220 povos e falantes de 180 línguas ${ }^{1,2}$. Os programas de saúde destinados a esta população têm dado ênfase à organização dos serviços, à viabilização de infra-estrutura e às tentativas de levantamentos epidemiológicos, pilares de um modelo médico ocidental cuja base conceitual visa à cura, restrita principalmente ao componente físico da doença ${ }^{3}$.

Atualmente, a assistência, neste modelo, conta com a ajuda de uma tecnologia levedura, na qual prevalece a medicalização, o uso de equipamentos, e os hospitais. O processo de trabalho, cada vez mais individualizado, enfraquece o controle social e desvaloriza a lógica indígena de saúde ${ }^{4,5}$.

No que tange à odontologia, os relatos que descrevem as representações e apropriações indígenas acerca das informações ocidentais em saúde bucal são escassos. O que existe são trabalhos quantitativos, não longitudinais e sem a presença da visão indígena sobre as mudanças ocorridas, sejam elas positivas ou não ${ }^{6,7}$.

A assistência em saúde bucal em Terra Wajãpi é caracterizada por décadas de ausência da atenção, fato agravado pela trajetória de 
contato com a sociedade industrializada, que resultou em algumas mudanças no regime alimentar desse povo. Além disso, considerase que a formação estritamente biológica dos profissionais de saúde facilitou a inserção de inúmeros componentes da odontologia tradicional ocidental, como o flúor, a escova, creme e fio dental, sem uma preocupação prévia das representações e práticas da higiene, da saúde ou da doença deste povo.

Dentro deste contexto, o presente estudo foi desenvolvido através de uma pesquisa quali-quantitativa cujos objetivos principais foram: a descrição de alguns aspectos das representações sócio-culturais dos Wajãpi; identificação dos hábitos e das transformações nos padrões alimentares deste povo ao longo da trajetória de contato com as práticas de assistência em saúde; e a análise de como este contexto repercute no perfil epidemiológico em saúde bucal dos Wajãpi/AP.

\section{Um pouco da História e das} Representações Sócio-Culturais dos Wajãpi /AP

Os Wajãpi são um povo de tradição e língua Tupi-Guaranique vivem na macro-região Norte, na fronteira entre o Brasil e a Guiana Francesa, no Estado do Amapá. Esta população, ao longo de sua história de aproximação com a sociedade envolvente, emprendeu "sucessivas migrações rumo ao norte, desde sua área de origem, no curso baixo do rio Xingu (...) escapando das frentes de colonização e dos empreendimentos missionários no baixo Amazonas" ${ }^{8}$. A população que ocupa o lado brasileiro dividese em subgrupos territoriais, em duas áreas: no Parque Indígena do Tumucumaque (Estado do Pará) e na Terra Indígena Wajãpi (Estado do
Amapá) ${ }^{9}$.

Em 1996, a Terra Indígena Wajãpi foi homologadapelo decreto 1.775 , que estabeleceu uma área de 607.017 hectares localizada na região centro-oeste do estado do Amapá. Sua extensão geográfica abrange os municípios de Laranjal do Jari (60,0\%) e de Pedra Branca do Amapari (40,0\%), correspondendo a 4,2\% do território amapaense ${ }^{10,11}$.

Ao final de 2004, a população da Terra Indígena Wajãpi foi contabilizada em 684 indivíduos, 343 homens $(50,14 \%)$ e 341 mulheres $(49,85 \%)$ vivendo em núcleos familiares, amplamente dispersos entre as 46 aldeias permanentes e/ou acampamentos temporários distribuídos pela Terra Indígena ${ }^{3,}$ 12.

O tipo e a localização das habitações estão intimamente relacionados às atividades agrícolas, à caça, à pesca e à coleta de frutas e sementes, principais meios de subsistência dos Wajãpi. Adicionado a isto, considere-se o fato de que muitas destas aldeias assumem posições estratégicas no que tange à proteção dos limites demarcados da Terra Indígena.

O sistema produtivo existente consiste na produção para o consumo e subsistência das famílias e não na ênfase de seu excedente. A organização sócio-política "baseia-se na ampla dispersão dos grupos familiaes pelo território, remetendo ao valor positivo que esta sociedade atribui à autonomia econômica e política de cada grupo" $"$.

O modo de vida Wajãpi é assegurado pelo caráter de união, entre os membros da comunidade e garantido pelo ritmo 
tranquilo do seu cotidiano. No entanto, esta tranquilidade é muitas vezes compreendida pela sociedade envolvente como uma letargia física e mental que expõe o povo Wajãpi ao jargão de "preguiçoso". Porém, o modo de vida dos Wajãpi não é um carpe diem desnorteado, e sim uma contextualização da necessidade de viver o presente, sem especular o futuro, mas, principalmente, respeitando o passado e as experiências dos diferentes grupos existentes.

No que tange ao processo saúde-doença e os seus comportamentos associados, os Wajãpi vivenciam esta dinâmica através de duas grandes categorias: o sistema ou lógica de agressão por espíritos chamados, entre outros nomes, $\tilde{A} j a \tilde{a}$, entendida como uma agressão mágica desencadeada por esta categoria genérica de ser não humano e que demanda um comportamento ético adequado pelo indivíduo doente; e o Ojipy, interpretado como uma contaminação mágica deflagrada pelo contato com certos fluídos, objetos ou pessoas ${ }^{13}$. Esta compreensão do processo saúde-doença entre os Wajãpi está voltada para o âmbito espiritual, mas, atualmente, vem sofrendo forte influência do discurso biomédico que impõe um sistema hermético de combinação de sintomas, para descrever e enquadrar as doenças.

\section{Abordagem Metodológica: Uma aproximação etnográfica}

A pesquisa etnográfica valoriza a concepção indígena de saúde, na medida em que possibilita a descrição de um sistema de significados culturais, sem emitir juízos de valor. Esta abordagem qualitativa observa e descreve a organização sócio-cultural de um grupo, destacando as concepções referentes a um recorte contextual sem desconectá-lo do seu meio. Este método de investigação social deve ser entendido não somente como uma reprodução das representações culturais, mas como uma construção a partir do olhar reflexivo onde o pesquisador exerce o papel subjetivo de participante e o papel objetivo de observador ${ }^{14-16}$.

Neste estudo, o trabalho de campo e a análise dos dados foram pautados pela imersão dos pesquisadores na área Wajãpi do Amapá, e pela técnica de triangulação dos registros escritos, observacionais e discursivos.

Entende-se por registros escritos o diário de campo do pesquisador composto de reflexões e anotações referentes aos indicadores epidemiológicos já levantados pelo Programa de Saúde Wajãpi (PSW).

Por registros observacionais entendese o conjunto de fatos acompanhados pelo pesquisador através da observação participante dos costumes, festas, rituais, gestos e expressões particulares que vieram a ter relação direta com a concepção Wajãpi do processo saúde-doença.

Já os registros discursivos constaram de entrevistas semi-estruturadas individuais, com os caciques, lideranças, professores e agentes indígenas de saúde (AIS), sobre temas variados como a identificação das práticas de higiene bucal, as narrativas míticas, os hábitos e as mudanças no padrão alimentar ao longo da trajetória de contato a sociedade nacional. Estas entrevistas tiveram como objetivo conhecer as representações dos entrevistados sobre o processo saúde-doença, possíveis mudanças no padrão alimentar, além dos cuidados com a boca e com os elementos dentários. 
Dentro deste contexto, esta pesquisa almejou aproximar-se ao máximo dos marcos teóricos da etnografia tendo sempre como pano de fundo, as relações sociais, culturais e ambientais dos Wajãpi.

Este estudo teve aprovação da Comissão Nacional de Ética em Pesquisa (CONEP) através do parecer $\mathrm{n}^{\circ} 1.646 / 2004$.

A imersão à Terra Indígena Wajãpi permitiu que as observações diárias dos pesquisadores se materializassem em um 'roteiro vivo', e a contextualização dos fatos vivenciados possibilitava uma entrevista mais próxima da realidade dos entrevistados.

A triangulação dos registros escritos, observacionais e discursivos nortearam profundas descrições sobre os temas por parte do pesquisador. Tais descrições foram agrupadas em textos temáticos que, checados sistematicamente, apontaram para temas que merecem um olhar diferenciado por parte da equipe de saúde bucal em Terra Wajãpi.

No entanto, os temas mais destacados possuíam íntima ligação ao advento da política de assalariamento pelas instituições de saúde, ao aparecimento de novos espaços de poder, à proximidade dos grandes centros, à introspecção da cosmologia e à mudança nos padrões alimentares desta população.

Dentro deste contexto, os resultados da análise dos registros discursivos, das anotações de campo e dos dados epidemiológicos foram agrupados em três eixos de análise: $A s$ Narrativas Míticas e a Interface com a Saúde Bucal; A Mudança no Regime Alimentar dos Wajãpi; e O Quadro Epidemiológico em
Saúde Bucal entre os Wajãpi. Estes três eixos orientaram a apresentação dos resultados.

\section{As Narrativas Míticas e a Interface com} a Saúde Bucal

“Antigamente Janejar pegou o palmito de pariri para fazer os dentes dos Wajãpi, por isso que, atualmente, os nossos dentes não duram muitos e muitos anos (...) Os dentes dos animais foram feitos da pedra Tãsi, por isso que os animais como a cutia, o veado e o catitu têm os dentes fortes" (Agente Indígena de Saúde)

Os fragmentos das narrativas míticas são um elemento, entre muitos outros, de um complexo ciclo de narrativas, que dão conta não apenas da origem dos dentes, mas de questões mais amplas. Logo, este estudo não se propôs a analisar as narrativas míticas, mas sim utilizar excertos de algumas delas, na tentativa de aproximar a odontologia e as representações culturais dos Wajãpi, no intuito de permitir que sejam mais bem compreendidas as formas de pensamento desta população a respeito do universo.

A prática odontológica tende a usar como pano de fundo a comparação entre o processo de saúde-doença ocidental e alguns elementos da cultura Wajãpi. No entanto, para isso continua a utilizar os mesmos instrumentos da lógica tradicional de saúde bucal, como as técnicas de escovação, a ênfase anatômica, a personificação de elementos dentários e os conceitos quanto à forma, número e função dos dentes. Este tipo de enfoque proporciona a simples transposição de práticas, a mera tradução dos elementos e não garante ações diferenciadas aos Wajãpi. 
O ideal seria que a equipe de saúde bucal soubesse ouvir a população para assim utilizar seu conhecimento, provocar seu pensamento e despertar seu interesse.

Portanto, é necessário que a equipe de saúde bucal seja capacitada em antropologia - por profissionais que dominem o assunto - para que assim utilize instrumentos e abordagens diferenciadas de promoção da saúde e com isso estreite o vinculo com a comunidade. Antes de 'sensibilizar' a população indígena perante o mundo da odontologia é imperativo que a própria equipe de saúde bucal esteja sensível às diferentes representações, hábitos e práticas de saúde já existentes. É válido salientar que a cultura de um povo não está reduzida às narrativas míticas e que os profissionais do campo da saúde precisam aprender a olhar sua própria cultura com um certo distanciamento, compreendendo assim que esta é uma entre muitas alternativas a serem utilizadas ${ }^{13}$.

Observou-se nas entrevistas, com referencia às narrativas míticas dos Wajãpi, uma certa diferença no pensar e agir entre os AIS e os demais entrevistados, quando o assunto é o processo saúde-doença. Percebeu-se um certo compromisso dos AIS com o discurso biomédico, como se este representasse o financiador do seu status, este oriundo da criação de novas esferas de influência e espaços de poder propiciados pela política de assalariamento aos povos indígenas pelas instituições de saúde.

O comprometimento dos AIS, com o discurso biomédico também pôde ser observado nos registros discursivos sobre os cuidados com a boca e com os elementos dentários, transparecendo a substituição das crenças, por conceitos e termos técnicos próprios da odontologia ocidental.

“O kurãpãnã é uma árvore que tem no mato...serve pra aquele sapinho da boca que é candidiase e serve também pra limpar os dentes pra os dentes ficarem forte, igual por exemplo como flúor" (Agente Indígena de Saúde)

“Tem...ypõsi...a gente pega galho bem fino, galho novo assim e pega e faz assim na mão (gesto de esfregar) e coloca na boca pra mastigar...não é pra engolir... é como remédio, se não dá dor de estômago" (Agente Indígena de Saúde)

"Com certeza (o kurãpãnã) é parente do flúor” (Agente Indígena de Saúde)

“O kurãpãnã a gente usa, como por exemplo, quando a gente vai caçar de manhã cedo; a gente corta pedaço né... aquele líquido sai...sai...sai...e não sai mesma hora não, sai três horas aquele líquido aqui...eu acho interessante é isso que é nossa preocupação também com os mais novos...como por exemplo os agentes de saúde é a turma nova não tão sabendo mais isso" (Professor Indígena)

A Mudança no Regime Alimentar dos Wajãpi/AP

“Antigamente não tinha tanta alimentação diferente, por exemplo, hoje em dia, tem sal, tem açúcar, tem leite, as coisas que a gente come hoje em dia é tudo misturado é tudo químico o que a gente come não é nem natural" (Professor Indígena) 
Os povos indígenas têm uma relação com a natureza que transcende a compreensão dos não índios. Essa representação tem íntima ligação com a origem do mundo e norteia o cotidiano dessa população. Não bastasse o aspecto cultural, é também da floresta que os povos indígenas retiram os elementos para a sua subsistência, através da agricultura, da caça, da pesca, da coleta de frutas e do artesanato, ficando bem evidente o impacto social, cultural e epidemiológico, resultante dos desequilíbrios acometidos à natureza.

Nos trabalhos que abordam o estado nutricional e as mudanças nos padrões alimentares dos povos indígenas do Brasil, têm sido uma constante a observação da relação desigual entre a distribuição de terra e a concentração populacional ${ }^{17,18}$. A população Wajãpi vivencia, por ora, um certo equilíbrio entre a distribuição de terra em relação a sua população ${ }^{13}$. Sendo assim, a limitação imposta pela escassez territorial não se configura como responsável pela mudança no regime alimentar dos Wajãpi, mas sim três componentes paralelos da trajetória de contato com a sociedade envolvente: o processo de sedentarização, a introdução de novos alimentos e ainda, a política de assalariamento.

Até meados de 1980, os Wajãpi responderam, tradicionalmente, ao processo de sedentarização, pois mesmo com a implantação do posto de atração da FUNAI, em 1973, ainda vigorava a tradição de intensa movimentação entre as aldeias e o ritmo sazonal de subsistência de cada família. Neste período, não há relatos da introdução de alimentos, pela FUNAI, mas há queixas da comunidade em relação à concentração populacional e à escassez de alimentos ${ }^{13}$.
Ao final da década de 1980, começam a surgir uma maior quantidade de postos de saúde, em virtude do início da implementação de políticas de saúde e das ações de missionários. Estas ações aglutinaram a população em três aldeias principais: Taitetuwa, Ytuwasu e Mariry. Com isso, as mesmas estimularam o movimento natural da comunidade de ir ao encontro dos 'novos postos de atração' 13 .

Paralelamente, surgem nas escolas experimentos com merenda causando certa confusão no entendimento dos Wajãpi de que a alimentação era somente para os alunos e não para toda a comunidade. Neste momento, os únicos que tinham um contato mais intenso com os alimentos dos não índios eram os indivíduos doentes que ficavam internados, nos postos de saúde, ou que iam para a cidade fazer exames ou cuidar da saúde. Estas idas e vindas despertaram o gosto por novas modalidades de alimento. Porém poucos eram os Wajãpi que detinham recursos financeiros para adquirir os gêneros alimentícios da cidade.

Ao final de 1999, intensificaram-se os cursos de formação e o pagamento de salário para os AIS, fato que repercutiu, com certa pressão, para que os professores indígenas também fossem remunerados. À medida que mais integrantes das famílias iam sendo incorporados à folha de pagamento, menor era a pressão dos núcleos familiares mais conservadores, fato que facilitava o crescimento do gosto e do costume de adquirir os alimentos do não índio. Sendo assim, esta situação possibilitou o aparecimento de novos espaços de poder, através da oferta de empregos para professores, AIS, agentes de saneamento, pilotos fluviais e pilotos terrestres. Os jovens se constituíram no público preferido desta política de assalariamento devido à 
fluência bilíngüe e ao oportuno desejo em adquirir os mesmos produtos que as equipes de saúde trazem consigo.

“Antigamente nós não comíamos comida do branco por isso nossos avós não tem dente estragado, agora atualmente nós recebemos (salário) e fomos para cidade e trouxe muita comida do karaikõ (não índio)”

\section{(Agente Indígena de Saúde)}

\section{O Quadro Epidemiológico em Saúde Bucal entre os Wajãpi}

"Antigamente, nós não ficamos preocupados se nosso dente vai estragar com aquilo que a gente usa, por exemplo kurãpãnã do mato serve bem para isso; a gente só faz lavar nossa boca...então quer dizer que nossos dentes eram fortes hoje em dia nossos dentes tão fracos eu vejo que lavamos bastante e mesmo assim estraga” (Professor Indígena)

A população indígena Wajãpi dispõe de atendimento odontológico sistematizado em área indígena desde 2001, por meio das ações da equipe de saúde bucal do Distrito Sanitário Especial Indígena (DSEI) do Amapá e Norte do Pará, em parceira com Organizações Não Governamentais (ONG). No início de 2002, a equipe de saúde bucal do mencionado DSEI realizou um levantamento coletivo em Terra Wajãpi e pode constatar que $73,2 \%$ da população pesquisada necessitava imediatamente de múltiplos procedimentos restauradores e/ou cirúrgicos (tabela 1).

No período de 2002 a 2004, o Programa de Saúde Wajãpi estabeleceu como missão, o estreitamento do vínculo com a comunidade, pois percebeu que as barreiras lingüísticas e as representações sócio-culturais necessitavam de estratégias distintas das atividades que o saber

Tabela 1. Levantamento das necessidades coletivas em saúde bucal, na população Wajãpi, 2002.

\begin{tabular}{lcccccc}
\hline Necessidades & $\mathrm{N}^{*}$ & $\%$ & Higido & Desdentado & A restaurar & A extrair \\
\hline $\begin{array}{l}\text { Nenhuma pessoa precisando } \\
\text { restaurar ou extrair dentes** }\end{array}$ & 96 & 26,8 & 74 & 22 & - & - \\
$\begin{array}{l}\text { Pessoas com até 3 dentes para } \\
\text { restaurar ou extraír** }\end{array}$ & 194 & 54,2 & - & - & 92 & 102 \\
$\begin{array}{l}\text { Pessoas com 4 a 8 dentes para } \\
\text { restaurar ou extraír** }\end{array}$ & 64 & 17,9 & - & - & 20 & 44 \\
$\begin{array}{l}\text { Pessoas com 8u + dentes para } \\
\text { restaurar ou extraír** }\end{array}$ & 04 & 1,1 & - & - & 01 & 03 \\
$\begin{array}{l}\text { Pessoas com dor de dente } \\
\text { (emergência) }\end{array}$ & 51 & 14,2 & - & - & - & - \\
$\begin{array}{l}\text { Pessoas com problema } \\
\text { periodontal (gengiva) }\end{array}$ & 58 & 16,2 & - & - & - & - \\
\hline
\end{tabular}

Fonte: Relatório Odontológico do PSW, 2002

* $\mathrm{N}=358$, representa $56 \%$ da população Wajãpi.

** Necessidades mutuamente excludentes 
odontológico dispunha. Para tal, foi enfatizado o fortalecimento dos AIS perante as lideranças e a comunidade, através da construção de instrumentos para que os mesmos realizassem suas atividades preventivas e educacionais sem necessitar dos recursos pré-moldados e utilizados pela odontologia junto à população não índia ${ }^{19}$.

No entanto, a falta de informações mais detalhadas quanto ao perfil epidemiológico em saúde bucal da população ainda era um grande empecilho para o desenvolvimento de ações diferenciadas entre as aldeias em área Wajãpi. Centrado neste contexto, esta pesquisa tentou compreender a prevalência e a história da doença cárie dental entre os Wajãpi analisando os dados coletados durante a rotina de serviço da equipe de saúde bucal durante o ano de 2003.

A distribuição da cárie dentária entre os Wajãpi/AP foi analisada através do índice CPO-D, que é a expressão numérica dos elementos dentários cariados, perdidos e obturados analisados. Porém, outras variáveis foram agregadas a esta análise, tais como: a localização geográfica das aldeias, a possibilidade de acesso aos diferentes serviços odontológicos (educativo, preventivo e curativo) e a trajetória com os diferentes agentes de contato.

Atualmente, em Terra Wajãpi existem 46 aldeias permanentes e/ou acampamentos temporários distribuídos em 607.017 hectares. Estas aldeias apresentam particularidades quanto ao acesso geográfico, seus núcleos familiares e ao contato com os diferentes segmentos da sociedade nacional.
Para efeito do estudo, as aldeias foram agrupadas em quatro regiões que mais se assemelhavam quanto às suas especificidades territoriais e populacionais:

Núcleo 1: Engloba as aldeias que têm como característica o acesso facilitado para automóveis, devido estarem localizadas próximas às estradas. Estas aldeias abrangem 179 indivíduos e representam $28 \%$ da população total. No estudo, foram examinadas 59 pessoas $(27,5 \%)$.

Núcleo 2: Engloba as aldeias que têm como característica o acesso terrestre em conjunto com o fluvial, bem como a presença de núcleos familiares mais tradicionais. Estas aldeias possuem juntas 185 indivíduos e representam $29 \%$ da população. No estudo, foram examinadas 61 pessoas $(29 \%)$.

Núcleo 3: Engloba as aldeias que têm como característica o acesso terrestre em conjunto com o fluvial, bem como a presença de núcleos familiares mais tradicionais. Estas aldeias são semelhantes às do núcleo 2, mas tem uma história familiar que as separa; possuem 234 indivíduos e representam $36,6 \%$ da população. No estudo, foram examinadas 76 pessoas $(36 \%)$.

Núcleo 4: Engloba as aldeias que estão localizadas no curso médio do 'Riozinho' que constitui o limite sudeste da Terra Indígena Wajãpi e têm como característica principal a proximidade geográfica e as relações com não indígenas de fundamentação religiosa. Estas aldeias possuem juntas 42 indivíduos e 
representam $6,4 \%$ da população. No estudo, foram examinadas 15 pessoas $(6 \%)$.

A metodologia utilizada deteve-se na análise dos dados secundários coletados dentro do Programa de Saúde Wajãpi (PSW) em 2003. Os exames foram realizados, exclusivamente, pelo cirurgião dentista do PSW e anotados pela auxiliar de cirurgião dentista $(\mathrm{ACD})$ do programa.

A amostra constou de 211 indivíduos (33\% do total) de ambos os sexos (103 feminino e 108 masculino), sendo a idade média 25,0 $( \pm 14,85)$ e a moda, 21 anos (tabela 2$)$.

Tabela 2. Distribuição da cárie dentária segundo faixa etária (CPO-D médio) no povo Wajãpi.

\begin{tabular}{cccc}
\hline $\begin{array}{c}\text { Faixa etária } \\
\text { (anos) }\end{array}$ & $\mathrm{N}$ & $\begin{array}{c}\text { CPO-D } \\
\text { (média) }\end{array}$ & $\begin{array}{c}\text { Desvio } \\
\text { padrão }\end{array}$ \\
\hline 6 & 4 & 1,5 & 0,57 \\
7 a 12 & 36 & 2,8 & 1,65 \\
13 a 24 & 89 & 6,9 & 3,47 \\
25 a 36 & 40 & 11,1 & 5,78 \\
37 a 48 & 24 & 10,2 & 6,85 \\
49 a 60 & 10 & 18,6 & 7,24 \\
61 a 72 & 7 & 16,9 & 5,64 \\
> 73 & 1 & 14,0 & 0,00 \\
Total & 211 & 8.2 & 6,04 \\
\hline
\end{tabular}

Fonte: Relatório Odontológico do PSW, 2003

Os dados foram analisados, a partir do programa EPI-INFO 3.2 e o CPO-D médio encontrado foi de 8,2 $( \pm 6,04)$. Quando analisados separadamente os componentes do índice CPO-D, observou-se que a média dos dentes perdidos foi $5,1( \pm 6,47)$, dos cariados, $2,4( \pm 1,92)$ e dos obturados, $0,6( \pm 1,10)$.

Este quadro deixa transparecer as décadas de ausência de uma assistência odontógica mais integral em área indígena Wajãpi e a clara ação de uma prática emergencial, curativa e mutiladora onde os dentes perdidos representam cerca de $62,0 \%$ do CPO-D, a necessidade acumulada ainda é bem evidente e os elementos cariados e obturados podem ser mais facilmente relacionados, numa visão da doença, ao distanciamento geográfico e à falta de recursos tecnológicos da sociedade médica ocidental. No entanto, para uma análise da saúde, este quadro é o retrato fiel das décadas de uma odontologia desarticulada da sociedade e dos outros segmentos da saúde e da educação.

Quando analisado o CPO-D médio de acordo com o gênero (dados não mostrados em tabelas), observou-se elevados valores nas mulheres 9,8 $( \pm 6,7)$ em relação aos homens $6,5( \pm 4,8)$. Sendo que o diferencial nesta relação se deu exclusivamente no componente perdido, onde o número de dentes extraídos em mulheres foi o dobro do número de dentes extraídos nos homens.

O CPO-D médio aos 12 anos encontrado entre os Wajãpi foi de 3,7. Constatou-se que este valor era mais elevado do que a média de 3,1 relatada pelo levantamento do Ministério da Saúde (Projeto SB Brasil 2003) para a população em geral da região norte, na mesma idade ${ }^{20}$. No entanto, é valido salientar que aos dados produzidos na rotina do serviço tendem a superestimar a prevalência da doença cárie dentária.

A distribuição da doença cárie dentária entre os Wajãpi se apresenta amplamente dispersa em área indígena, independentemente de distinções quanto ao acesso geográfico, aos núcleos familiares e ao contato com os diferentes segmentos da sociedade nacional que cada núcleo das aldeias possa ter. Em 
outras palavras mais quantitativamente inteligíveis, quando analisado o CPO-D considerando a localização das aldeias não foi observada nenhuma diferença estatisticamente significante (tabela 3 ).

Tabela 3. Média de CPO-D segundo os núcleos das aldeias no povo Wajãpi.

\begin{tabular}{ccc}
\hline $\begin{array}{c}\text { Núcleo das } \\
\text { aldeias }\end{array}$ & $\begin{array}{c}\text { CPO-D } \\
\text { (média) }\end{array}$ & $\begin{array}{c}\text { Desvio } \\
\text { padrão }\end{array}$ \\
\hline Núcleo 1 & 8,97 & 6,6 \\
Núcleo 2 & 7,96 & 5,9 \\
Núcleo 3 & 7,40 & 5,1 \\
Núcleo 4 & 8,06 & 6,9 \\
Total & 8,17 & 6,0 \\
\hline
\end{tabular}

Fonte: Relatório Odontológico do PSW, 2003

$* x^{2}=1,3355 ; \mathrm{p}=0,7207$

No entanto, quando analisados separadamente os componentes do CPO-D, observou-se uma diferença quanto ao acesso ao tratamento restaurador e às extrações de acordo com a localização geográfica das aldeias. As localidades mais distantes apresentaram uma polarização dos elementos cariados e a necessidade do acesso ao tratamento odontológico, enquanto nas aldeias mais próximas das estradas e ao contato com missionários ficou mais evidente o elevado número de elementos dentários perdidos (tabela 4).

Tabela 4. Distribuição dos componentes do CPO-D, segundo os núcleos das aldeias Wajãpi.

\begin{tabular}{ccccc} 
& Núcleo & Núcleo & Núcleo & Núcleo \\
CPO-D & $\mathbf{1}$ & $\mathbf{2}$ & $\mathbf{3}$ & $\mathbf{4}$ \\
\hline & & & & \\
Cariado & 2,15 & 2,63 & 2,59 & 1,80
\end{tabular}

\begin{tabular}{lllll} 
Obturado & 0,68 & 0,25 & 0,84 & 0,93 \\
& & & & \\
Perdido & 6.03 & 4.32 & 3.68 & 5.26 \\
\hline
\end{tabular}

Fonte: Relatório Odontológico do PSW, 2003

\section{CONSIDERAÇÕES FINAIS}

A efetividade da atenção odontológica em área Wajãpi somente será possível quando a saúde bucal estiver mais integrada à comunidade, gestores, parceiros, AIS, agentes de saneamento e professores. Nesta mesma direção, a equipe de saúde bucal precisa ter em mente que os instrumentos proporcionados pelo pensamento biomédico não permitem conhecer, compreender e valorizar as práticas culturais existentes.

No que tange às referências sobre as narrativas míticas e a sua interface com a saúde bucal, é fundamental, que através desta via de acesso, se almeje uma maior aproximação entre a odontologia e as variadas formas de conhecimento, hábitos e práticas de cuidados em saúde. Esta iniciativa de aproximação da odontologia para com as narrativas míticas visa garantir uma relação de vínculo com a comunidade, sensibilizar a equipe de saúde bucal e estimular a construção de instrumentos culturalmente diferenciados. Para tal, faz-se necessário que as abordagens fragmentadas da boca e dos elementos dentários fora de um corpo integrado sejam abolidas, uma vez que a população Wajãpi não segmenta a idéia de corpo como estamos acostumados em nossa sociedade.

O valor da saúde bucal, para os Wajãpi, sempre esteve atrelado à necessidade de resolução do problema ou incômodo que se 
localiza na cavidade oral, quer seja mediante a utilização de plantas da floresta para aliviar a dor, quer seja pela utilização de fibras vegetais para a remoção de alimento entre os dentes. Atualmente, esta idéia está sendo substituída apenas pela troca de instrumentos mais avançados dos não-índios, sem uma reflexão intercultural das implicações dessa troca face a um discurso hegemônico que passou a ser concebido comoum dogmaincontestável.Logo, faz-se necessário modificar este entendimento ampliando a discussão de que com o aumento do consumo de alimentos industrializados, a noção de prevenção em saúde bucal terá que emergir aliada à contextualização da necessidade de novos componentes, como a escova, creme e fio dental.

Os registros observacionais apontam para a presença de um discurso técnico em saúde bucal intermediado pelos profissionais $\mathrm{e}$ repetido pelos AIS à comunidade, porém sob um pano de fundo que não condiz com a realidade cultural da população. Estas observações são respaldadas pelos registros discursivos dos Wajãpi que foram possíveis de serem realizados durante a estadia em campo, quanto ao processo saúde-doença, e que deixam transparecer a apropriação de elementos da odontologia ocidental tradicional a ponto de não distinguir se estes valores são componentes da cultura em questão ou da trajetória de contato com as ciências médicas.

Contudo, já se evidencia em Terra Wajãpi questionamentos da população sobre os cuidados de saúde bucal. Neste contexto, os Wajãpi estão aprendendo a objetivar uma nova prática de saúde bucal. Sendo este um momento oportuno para a construção de uma odontologia menos imposta e mais culturalmente diferenciada.

No que tange à mudança no regime alimentar dos Wajãpi, percebe-se que o contato com alimentos industrializados e seu consumo foram progressivamente aumentando na mesma medida que foram surgindo as atividades remuneradas em área indígena. Também houve um incremento na presença de profissionais não-indíos, que trazem grandes quantidades de alimentos industrializados para sua estada na área indígena (geralmente por períodos de 30 dias), estabelecendo com isso práticas de troca que aguçam o senso de curiosidade pelo novo, pelo colorido e por sabores diferentes destes alimentos.

Quanto ao quadro epidemiológico em saúde bucal, concluiu-se que a localização geográfica das aldeias, em Terra Wajãpi, pode estar proporcionando diferenças no acesso ao tratamento em saúde bucal, pois as aldeias da estrada e as aldeias que possuem maior proximidade com os agentes de contato - entre eles o religioso - apresentam uma polarização do componente 'perdido' em detrimento do componente 'obturado' das aldeias mais distantes.

Porém, é pertinente salientar que os dados coletados na rotina dos serviços e a complexidade dos fatores relacionados à trajetória de contato com a sociedade nacional demandam novas investigações para melhor entendermos a distribuição das doenças orais em Terra Wajãpi.

\section{AGRADECIMENTOS}

Agradecimento especial ao Povo Wajãpi, ao Conselho das Aldeias Wajãpi (Apina), à 
Coordenação de Aperfeiçoamento de Pessoal de Nível Superior (CAPES) e à Dominique T. Gallois pela discussão dos aspectos da pesquisa e do trabalho empírico junto aos wajãpi.

\section{REFERÊNCIAS}

1. Ministério da Justiça. Fundação Nacional do Índio. Índios do Brasil. www.funai.gov.br (acessado em 10/Dez/2011).

2. Ministério da Saúde. Fundação Nacional de Saúde. Política nacional de atenção à saúde dos povos indígenas. Brasília; 2000.

3. Coelho de Souza TA. Etnografia Wajãpi/ AP do processo saúde-doença: um enfoque odontológico [Dissertação de Mestrado]. Belo Horizonte: Faculdade de Odontologia, Universidade Federal de Minas Gerais; 2005.

4. Athias R. Índios, antropólogos e gestores de saúde no âmbito dos distritos sanitários indígenas. In: Langdon EJ, Garnelo L, organizadores. Saúde dos povos indígenas: reflexões sobre antropologia parcipativa. Rio de Janeiro: Contra capa livraria/Associação brasileira de antropologia; 2004. p. 217-32.

5. Mehry EE, Onocko R, organizadores. Agir em Saúde: um desafio para o público. São Paulo: HUCITEC; 1997.

6. Arantes R. Saúde bucal dos povos indígenas no Brasil: panorama atual e perspectivas. In: Coimbra Jr CEA, Santos RV, Escobar AL, organizadores. Epidemiologia e saúde dos povos indígenas no Brasil. Rio de Janeiro: Fiocruz; 2003. p. 49-72.

7. Arantes R, Santos RV, Coimbra Jr CEA.
Saúde bucal na população indígena Xavante de Pimentel Barbosa, Mato Grosso, Brasil. Cadernos de Saúde Pública, n. 17, p. 375-384, 2001.

8. Gallois DT. O Movimento na cosmologia Wajãpi: criação e transformação do universo [Tese de Doutorado]. São Paulo: Universidade de São Paulo; 1988.

9. Instituto Socioambiental. Povos indígenas no Brasil. http://www.socioambiental.org.br (acessado em 10/Ago/2004).

10. Programa Wajãpi/Centro de Trabalho Indigenista. A terra Wajãpi/AP e a problemática sócio-ambiental. Documento base. São Paulo; 1999.

11. Brasil. Decreto n. 1.775 de 24 de maio de 1996. Dispõe sobre a homologação da Terra Indígena Wajãpi/AP.

12. Iepe. Mapa da Terra Indígena Wajãpi, 31.05.2004 (mimeo)

13. Gallois DT. O regime alimentar dos Wajãpi/ AP e o processo saúde doença [Entrevista com Dominique T. Gallois]. Amapá: FO-UFMG; 2004.

14. Gonçalves JRS, organizador. A Experiência Etnográfica: antropologia e literatura no século XX/James Clifford. Rio de Janeiro: UFRJ; 1998.

15. Lüdke M, André MEDA. Pesquisa em educação: abordagens qualitativas. São Paulo: E.P.U; 1986.

16. Wilson S. The use of ethnographic 
techniques in educational research. Review of Educational Research 1977; 47: 245-65.

17. Coimbra Jr CEA, Santos RV, Escobar AL, organizadores. Epidemiologia e saúde dos povos indígenas no Brasil. Rio de Janeiro: Editora Fiocruz; 2003.

18. Ricardo CA, organizador. Povos Indígenas no Brasil 1996/2000. São Paulo: Instituto

Socioambiental; 2000.

19. Programa de saúde wajãpi / PSW. Relatório odontológico. Macapá, 2002-2004 (mimeo).

20. Ministério da Saúde. Secretaria de Atenção à Saúde, Departamento de Atenção Básica. Projeto SB Brasil 2003: condições de saúde bucal da população brasileira 2002-2003: resultados principais. Brasília; 2004. 